\title{
Ensino de Habilidades no Uso de Dinheiro a Idoso com Perda de Memória por Meio de Relações Condicionais e Equivalência
}

\author{
Rebeca Lopes Cavaletti \& João dos Santos Carmo* \\ Universidade Federal de São Carlos, São Carlos, Brasil; Instituto Nacional de Ciência e Tecnologia sobre \\ Comportamento, Cognição e Ensino, São Carlos, Brasil
}

\begin{abstract}
RESUMO
Objetivou-se avaliar e ensinar habilidades no uso de dinheiro a uma participante de 86 anos, com Alzheimer. Os estímulos foram numerais ditados (A), valor monetário ditado (A'), numerais impressos (B), figuras das notas (C), notas (C'), composições (D), nomeação (E), figuras das moedas (F), moedas (F'). Testaram-se BB, AB, A'C, CB, BC, DB, BD, BE, CE, CC', A'C', C'E, A'F, A'F', FF', BF, FB, FE e F'E. A participante apresentou de $80 \%$ a $100 \%$ de acertos, excetuando-se FE e F'E com 20\%, que foram ensinadas. Testes finais documentaram relações simétricas e transitivas e generalização para tarefas de compra em ambiente social. Ainda, contribuiu para a formulação de um conjunto de testes que verificam a capacidade financeira de idosos com Alzheimer.
\end{abstract}

Palavras-chave: doença de Alzheimer; habilidades no uso de dinheiro; idosos; equivalência de estímulos.

\section{ABSTRACT \\ Teaching money skills to an elderly with memory loss through conditional relations and equivalence}

The objective was to assess and teach monetary skills to an elderly woman of 86 years with Alzheimer. The stimuli were dictated numerals (A), dictated monetary value (A '), printed numerals $(B)$, figures of notes $(C)$, notes $\left(C^{\prime}\right)$, combinations $(D)$, naming $(E)$, pictures of coins $(F)$, coins $(F)$. Relations $\mathrm{BB}, \mathrm{AB}, \mathrm{A}^{\prime} \mathrm{C}, \mathrm{CB}, \mathrm{BC}, \mathrm{DB}, \mathrm{BD}, \mathrm{BE}, \mathrm{CE}, \mathrm{CC}$ ', A'C, C'E, A'F, FF', BF, FB, FE, F' $\mathrm{E}$ were tested. The participant showed $80 \%$ to $100 \%$ correct responses, except for $\mathrm{FE}$ and $\mathrm{F}^{\prime} \mathrm{E}$ with $20 \%$ which have been taught. Final tests documented transitive and symmetrical relations and generalization for purchasing tasks in a social environment. Also contributes to the formulation of a set of tests that verify the financial capacity of Alzheimer patients.

Keywords: Alzheimer's disease; money skills; elderly; stimulus equivalence.

A Doença de Alzheimer (DA) é uma doença neurodegenerativa progressiva tendo início gradual e declínio cognitivo contínuo. Caracteriza-se por déficits cognitivos, manifestados pelo prejuízo da memória e pelo comprometimento de uma (ou mais) função cognitiva (afasia, apraxia, agnosia, perturbação do funcionamento executivo - isto é, planejamento, organização, sequenciamento, abstração) (APA, 2003). Uma das primeiras manifestações em indivíduos com doença de Alzheimer (DA) é a dificuldade para cálculos e fatos numéricos básicos (Arnaud, Lemaire, Allen \& Michel, 2008; Deloche, Hannequin, Carlomagno \& Agniel, 1995; Maylor, Watson \& Muller, 2005; Parla- to, Lopez, Panisset \& Iavarone, 1992; Rosselli et al., 1998).

A aritmética e os fatos numéricos básicos podem ser definidos como um conjunto complexo de habilidades: cálculo com dígitos simples e cálculo com dígitos múltiplos (envolvendo tanto cálculos escritos quanto cálculo mental, ou seja, sem auxílio de recursos como papel e lápis); seguimento de algoritmos; subitização; procedimentos combinatórios (formação de conjuntos e subconjuntos; agrupamento; comparação); contagem; produção de sequência numérica verbal; identificação de numerais e quantidades; equi-

\footnotetext{
Endereço para correspondência: João dos Santos Carmo - jcarmo@ufscar.br
} 
valência entre numeral e quantidade em diferentes modalidades sensoriais (Mantovan, Delazer, Ermani \& Denes, 1999).

A perda de habilidades aritméticas, juntamente com a perda de memória e déficits de linguagem, decorrentes da DA, frequentemente dificulta a autonomia dos idosos em atividades de vida diária (AVD). Além de comprometimentos nas AVD's, indivíduos com DA apresentam déficits nas atividades instrumentais de vida diária, as AIVD's (Nygård, 2003) como, por exemplo, a capacidade de usar dinheiro em compras, uma vez que esta capacidade envolve habilidades básicas importantes, tais como discriminação, composição e comparação de valores; pagamento e recebimento de troco.

Essas habilidades de discriminação, comparação, planejamento e uso de dinheiro cotidianamente recebem o nome, na literatura internacional, de "capacidade financeira" (financial capacity). Alguns estudos foram produzidos com o objetivo de investigar essa capacidade em idosos com DA e com outras demências (Ernst et al., 2001; Marson, 2001; Martin, 2008; Martin et al., 2003). Marson et al. (2000) identificaram que indivíduos com nível inicial de DA apresentam déficits importantes em habilidades financeiras complexas (transações bancárias, gerenciamento de talão de cheques, tomadas de decisão em relação às finanças) e deterioração da maioria das atividades financeiras cotidianas, enquanto que em um nível moderado a deterioração da capacidade financeira é severa nas diversas habilidades componentes.

No entanto, os estudos sobre capacidade financeira em pacientes com DA são tipicamente avaliativos. Há, portanto, carência de investigações que implementem o ensino e o enriquecimento de habilidades no uso de dinheiro e alguns fatos aritméticos básicos.

Por outro lado, alguns estudos apontam para uma possível reversão da perda de memória em idosos saudáveis ou com demência e para a aquisição de habilidades necessárias ao desenvolvimento de tarefas diárias. Clare, Wilson e Carter (2000, 2001), Arkin (2000) e Kixmiller (2002) utilizaram o método de aprendizagem sem erro combinada com a recuperação espaçada. Tal proposta está baseada no condicionamento operante e se caracteriza pela exigência repetida de lembranças de novas informações adquiridas. As solicitações de lembranças repetidas ocorrem a intervalos de tempo cada vez mais espaçados e/ou com aumento gradual de itens intervenientes, e visa evitar que os erros na fase de aprendizagem possam ocorrer. Os participantes desses estudos mostraram melhora significativa na porcentagem de informações guardadas e relembradas depois das sessões de treino. Houve, ainda, resultados positivos com relação à duração das lembranças, sendo feitos testes de 1 a 24 meses após o treino. Tais estudos e seus resultados sinalizam que um tabu há muito mantido na sociedade, de que idosos não conseguem aprender e de que a perda de memória é irreversível, pode ser colocado em dúvida.

Outra possibilidade promissora para a aquisição de habilidades necessárias ao desenvolvimento de tarefas diárias é o ensino de discriminações condicionais a diferentes populações que não se beneficiam dos métodos tradicionais de ensino (Sidman, 2000). A discriminação condicional envolve uma contingência de quatro termos, e o procedimento de ensino mais empregado para estas relações é o de "escolha de acordo com o modelo" (matching to sample - MTS) (Catania, 1999). Quando relações condicionais são bem estabelecidas e estáveis, pode-se frequentemente também demonstrar relações de equivalência de estímulos (Sidman \& Tailby, 1982).

Pérez-González e Moreno-Sierra (1999) investigaram a aquisição e manutenção de discriminações condicionais e a emergência de novas relações durante o processo de envelhecimento normal. Participaram 10 pessoas com idades variando entre 13 e 74 anos. Foram ensinadas relações condicionais do tipo $\mathrm{AB}$ e $\mathrm{BC}$ e testadas as relações de simetria (BA e CB) e transitividade (AC). Todos os estímulos eram figuras geométricas bidimensionais. Participantes mais velhos aprenderam discriminações condicionais mais lentamente que os mais jovens. Entretanto, uma vez que estas relações eram aprendidas, novas relações entre esses estímulos emergiam de forma semelhante entre jovens e idosos. Esses autores ainda sugerem que o modelo de equivalência de estímulos pode ser útil inclusive para o planejamento de diferentes procedimentos de ensino e para a estimulação da memória em pessoas idosas.

Seria possível utilizar o modelo de equivalência de estímulos para avaliação e ensino de habilidades básicas no uso de dinheiro a idosos com perda inicial de memória? Conforme já sinalizado, não há na literatura estudos nessa direção. Portanto, para responder a essa questão, buscou-se um procedimento com resultados promissores com outras populações com déficits cognitivos. O estudo desenvolvido por Rossit e Goyos (2004) mostrou-se extremamente útil para os nossos 
objetivos. Nesse estudo estabeleceram-se discriminações condicionais por meio de MTS para analisar a aquisição de relações matemáticas, baseado no paradigma de equivalência de estímulos, e para ensinar 11 deficientes intelectuais a manusear dinheiro. Os estímulos experimentais foram palavras ditadas, numerais impressos, imagens de moedas e notas, numerais intercalados com sinais de adição, conjunto de moedas, notas e moedas juntas, preços impressos, moedas e notas verdadeiras. Os resultados foram positivos e demonstraram a eficácia dos procedimentos utilizados, constatada a aquisição de habilidades complexas num período de tempo reduzido. Os participantes formaram classes extensas de estímulos equivalentes e expandiram para valores não treinados e situação simulada de compra.

Como já há um precedente mostrando que idosos podem formar rede de relações equivalentes (PérezGonzález \& Moreno-Sierra, 1999), então é possível que o ensino de habilidades monetárias a idosos com perda de memória, utilizando-se o paradigma de equivalência e os controles e procedimentos sugeridos por Rossit e Goyos (2004), produza efeitos de aprendizagem de relações monetárias nessa população.

O presente estudo objetivou (a) sistematizar um conjunto de testes iniciais para verificação de habilidades numéricas e de uso de dinheiro em idoso com perda inicial de memória; (b) a partir dos resultados obtidos nos testes, programar estratégias de ensino para estabelecimento de habilidades no uso de dinheiro; (c) verificar a generalização das habilidades aprendidas para situações cotidianas.

\section{MÉTODO}

\section{Participante}

Uma idosa de 86 anos de idade, previamente diagnosticada com Doença de Alzheimer por um neurologista. Segundo relato da cuidadora, a participante apresentava dificuldades para lidar com dinheiro no dia a dia. Concluiu seus estudos apenas até a $3^{\mathrm{a}}$ séria do antigo Primário, mas possuía uma boa fluência em leitura. Sua escrita era um pouco prejudicada por tremores das mãos. Devido ao diagnóstico de DA, a idosa estava sob o efeito de alguns medicamentos (Midazolan, Assert - sertralina e Amplictil). Não possuía outros problemas de saúde tais como diabetes e hipertensão, mas havia uma suspeita de Doença de Parkinson em fase inicial. Morava sozinha em uma casa térrea, e a cuidadora, contratada pelos filhos da parti- cipante, estava presente desde o final da tarde até o outro dia de manhã. Dois testes padronizados foram aplicados inicialmente: o Mini-Exame do Estado Mental para avaliação cognitiva (Brucki, Nitrini, Caramelli, Bertolucci \& Okamoto, 2003) e o AVD-Katz para uma avaliação das atividades diárias (Katz, Ford, Moskowitz, Jackson \& Jaffe, 1963). A idosa apresentou alteração na pontuação no Mini-Exame do Estado Mental (14/24), sendo essa referente a índices menores do que a nota de corte designada para a escolaridade da idosa. As diferentes pontuações obtidas com o AVD-Katz não foram conclusivas. O Termo de Consentimento Livre e Esclarecido foi assinado por uma das filhas.

\section{Material e Ambiente Experimental}

Foram utilizados durante o estudo, papel-moeda, moedas, cartões impressos contendo os estímulos experimentais, objetos utilizados no dia a dia da idosa para a composição da miniloja, um notebook (Dell Inspiron 1525) para a execução dos procedimentos de discriminações condicionais referentes à primeira fase do estudo e uma prancha para o arranjo das tarefas de escolha de acordo com o modelo disposta sobre a mesa. Essa prancha continha um espaço no meio da parte superior para que o estímulo-modelo fosse colocado sempre na mesma posição e três espaços abaixo para que os estímulos de comparação também fossem colocados sempre na mesma posição, garantindo um controle de disposição dos mesmos e evitando variáveis intervenientes, como grande variação no espaçamento entre os estímulos.

A coleta foi conduzida na sala de estar da residência da idosa. Programou-se o ambiente de coleta de dados para que o mesmo tivesse o mínimo de interferência externa durante as sessões de coleta.

\section{Conjuntos de Estímulos e Respostas}

Os estímulos utilizados durante o estudo estão parcialmente baseados no estudo de Rossit e Goyos (2004).

Os estímulos auditivos utilizados foram divididos em dois conjuntos sendo, Conjunto A: nomes ditados dos numerais $(2,5,10,20,25,50$ e 100); e Conjunto A': valores monetários (" $0,05 "$, " $0,10 "$, " 0,25 ", " $0,50 "$, " $1,00 "$, " $2,00 "$, "5,00", " $10,00 "$, " $20,00 ”$, "50,00", "100,00"). Como estímulos visuais, o Conjunto B: numerais impressos $(2 ; 5 ; 10 ; 20 ; 25 ; 50 ; 100$; " $0,05 " ; ~ " 0,10 " ; ~ " 0,25 " ; ~ " 0,50 " ; ~ " 1,00 " ; ~ " 2,00 " ;$ "5,00”; “10,00”; “20,00”; “50,00” e "100,00”); Con- 
junto C: figuras das notas de " $2,5,10,20,50$ e 100"; Conjunto C': notas de " $2,5,10,20,50$ e 100"; Conjunto D: numerais intercalados com o sinal da adição $(1+1), \quad(2+2+1), \quad(1+1+1+1+1), \quad(5+5), \quad(5+2+2+1)$, $(10+10), \quad(10+5+5), \quad(20+5),(10+10+5),(25+25)$, $(20+20+10),(50+25+25)$ e $(50+50)$; Conjunto E: nomeação pelo participantes dos seguintes valores: $2 ; 5$;

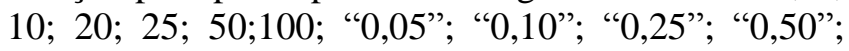
"1,00"; “2,00"; "5,00"; "10,00"; "20,00"; "50,00" e "100,00"; Conjunto F: figuras das moedas de "5, 10, 25 e 50 centavos e 1 real"; Conjunto F': moedas de " $5,10,25$ e 50 centavos e 1 real" e; Conjunto G: preços impressos combinando valores ensinados durante todo procedimento, sendo as combinações com os seguintes valores: " $1,00 ", " 2,00 ", " 5,00 ", " 10,00 "$, “20,00", " $50,00 "$ e " $100,00 "$ reais e " $0,05 "$, " $0,10 "$, “ 0,25 " e " 0,50 " centavos.

Para a situação de adaptação do idoso às tarefas de MTS, foram utilizadas seis figuras de pessoas famosas (que estão ou estiveram na mídia por algum tempo): "Pelé", "Chacrinha", "Carmem Miranda", "Elvis Presley", "Roberto Carlos" e "Orlando Silva".

Parte das tarefas de discriminação condicional foi apresentada no computador, enquanto que as tarefas que se referem à manipulação de dinheiro real foram apresentadas sobre uma mesa, em um ambiente programado para ser uma loja e em uma loja de conveniências próximo à casa da idosa.

\section{PROCEDIMENTO GERAL}

\section{Tarefas de Escolha de Acordo com o Modelo (MTS)}

Esse procedimento caracterizou-se pela apresentação de um estímulo-modelo na parte superior da tela do computador ou na parte superior da prancha. A resposta de observação da participante foi apontar para o modelo. Após apontar, três estímulos de comparação eram apresentados abaixo do modelo, na tela do computador ou na prancha, conforme o caso. A resposta da participante consistiu na escolha de um estímulo de comparação apontando-o. O requisito foi que a participante discriminasse inicialmente entre $o$ estímulo-modelo apresentado, sucessivamente, ao longo das tentativas e dentre os estímulos de escolha apresentados, simultaneamente, em cada tentativa.

As tarefas de escolha de acordo com o modelo foram utilizadas durante o procedimento que envolve discriminação. Em tarefas de ensino, escolhas corretas foram seguidas por elogio verbal, tais como "muito bom" e "parabéns" e a apresentação da próxima tentativa. Escolhas incorretas foram seguidas por um procedimento adicional de auxílio, que consistia em uma instrução oral, "Qual é a nota/moeda?" para que a participante nomeasse o estímulo-modelo e os estímulos de comparação, juntamente com a resposta de observação ao modelo (apontar) já requerida anteriormente, seguida da reapresentação da tentativa. A próxima tentativa era apresentada logo após o acerto da participante. Em tarefas de teste não houve diferenciação para respostas corretas ou incorretas. Cada tarefa conteve entre dez e vinte tentativas e cada estímulo de comparação apareceu o mesmo número de vezes não sendo repetido mais que duas vezes consecutivas na mesma posição. $\mathrm{O}$ critério das tarefas de discriminação condicional foi de $100 \%$ de acertos em um bloco, no caso dos testes e dois blocos consecutivos de $100 \%$ de acertos no caso de ensino.

\section{Procedimentos de Coleta de Dados}

Para avaliar as habilidades matemáticas presentes no repertório da idosa e para o ensino das mesmas foi utilizado parte do procedimento desenvolvido por Rossit e Goyos (2004).

Inicialmente foi conduzido um treino preparatório de identidade, no computador, com figuras familiares de pessoas famosas, com a finalidade de instalar comportamentos essenciais para responder condicionalmente (olhar para o estímulo-modelo, apontá-lo como uma resposta de observação, olhar para os estímulos de comparação, selecionar um deles em resposta ao modelo e receber consequências para escolhas corretas e incorretas). Após esse treino foi conduzido um treino de nomeação, com as mesmas figuras para que a participante aprendesse a tarefa. Foi solicitado à participante que nomeasse figuras de pessoas famosas quando essas aparecessem na tela. Ambos os treinos tinham como critério apenas um bloco com $100 \%$ de acertos. Um procedimento de correção em que o experimentador produzia em voz alta o nome/sobrenome do modelo e requisitava que a participante ecoasse, foi aplicado quando necessário.

A primeira fase do estudo foi introduzida logo após a conclusão do treino de MTS. Ela consistiu na realização de testes das relações condicionais presentes nas Figuras 1 e 2 por meio de MTS e em extinção a fim de mapear o repertório de entrada da participante. 


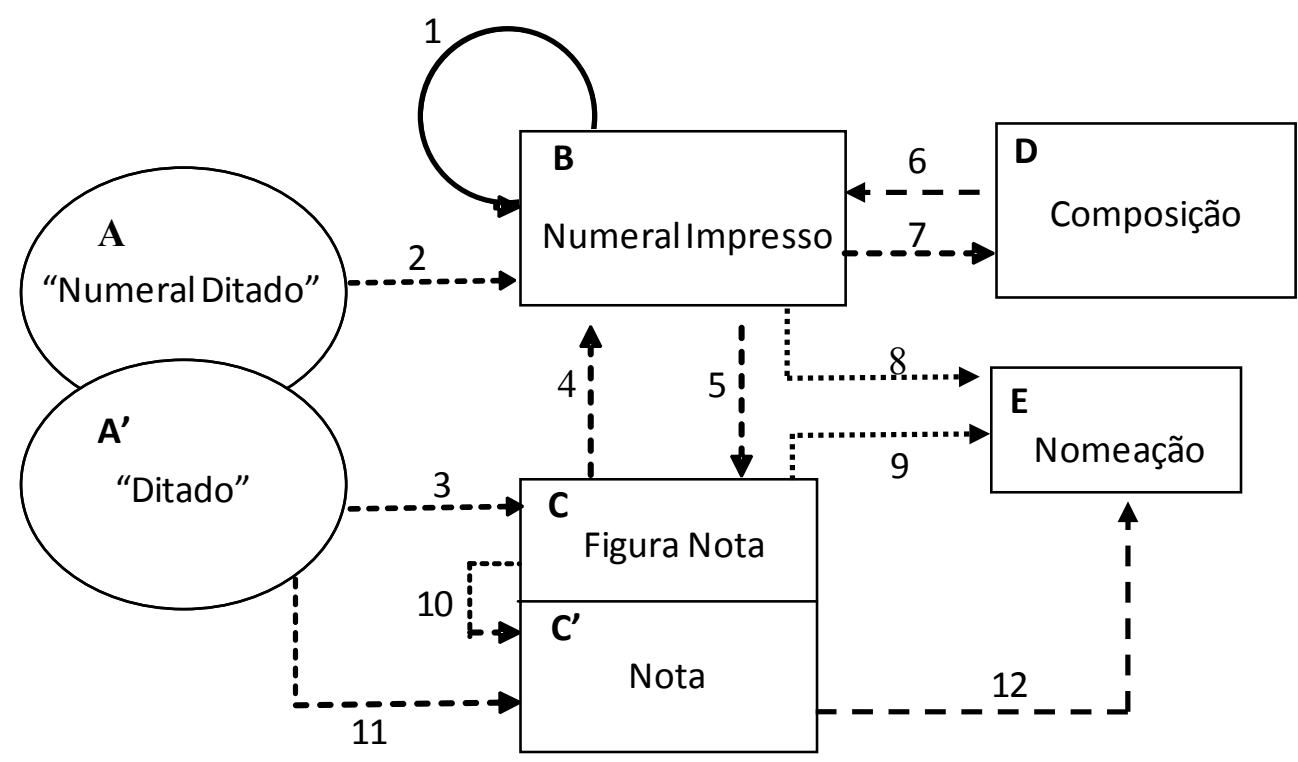

Figura 1. Rede de relações condicionais utilizada no estudo de Rossit e Goyos (2004) e implementada na primeira fase da coleta do presente estudo. As caixas representam o conjunto de estímulos. As setas sinalizam as relações a serem testadas. Os numerais designam a sequência de ensino e/ou teste.

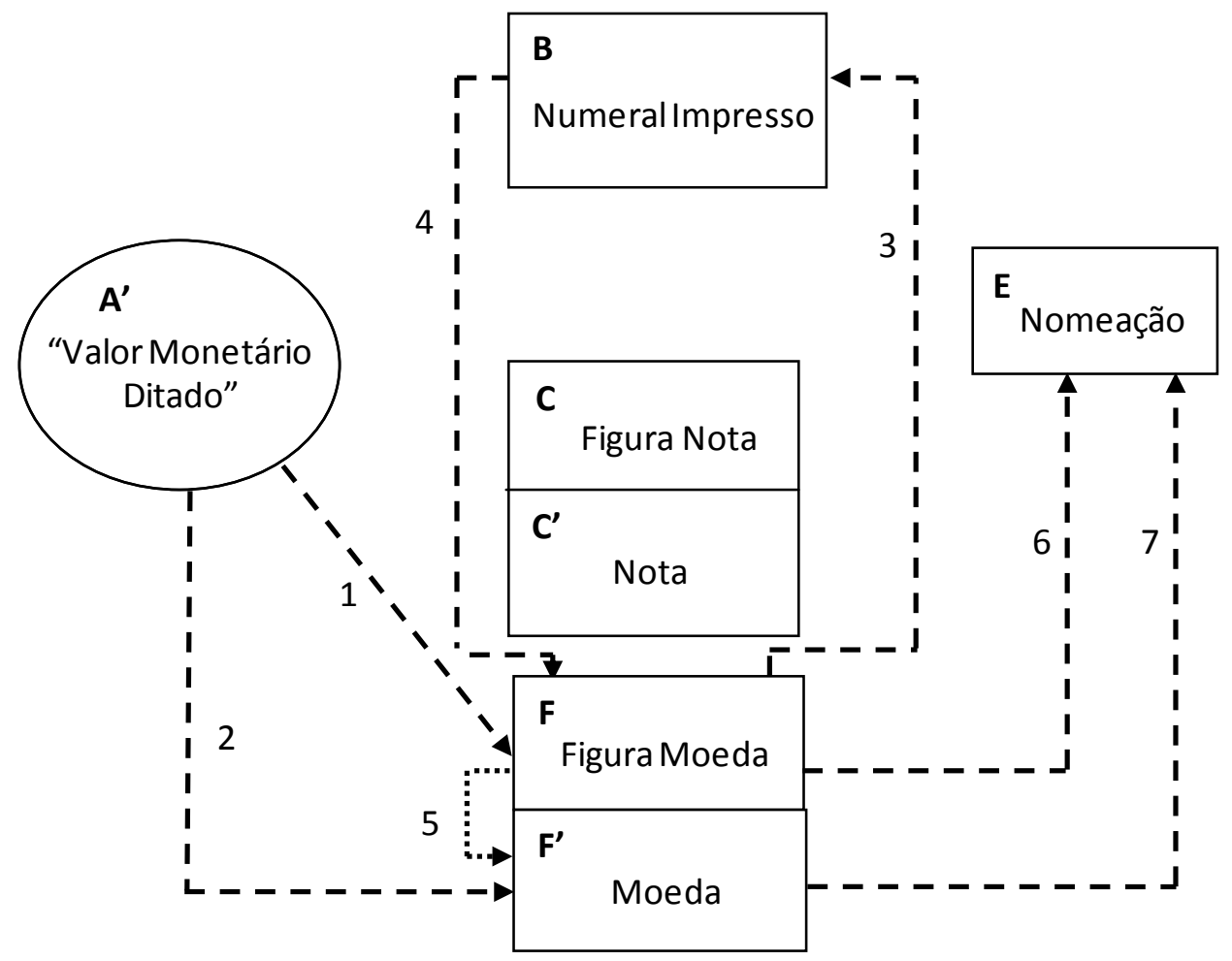

Figura 2. Rede de relações condicionais. As caixas representam o conjunto de estímulos. As setas sinalizam as relações a serem testadas. Os numerais designam a sequência de ensin̄o e/ou teste (adaptado de Rossit \& Goyos, 2004). 
Ainda na primeira fase, após a realização dos testes, houve o ensino de uma das relações em que o acerto da participante foi ao nível do acaso. $\mathrm{O}$ critério de acertos foi de dois blocos consecutivos de $100 \%$ de acertos.

Na segunda fase, três tarefas foram primeiramente testadas. Essas tarefas foram apresentadas sobre a prancha. A primeira tarefa consistiu na apresentação de uma nota ou de uma moeda como estímulo-modelo e três estímulos de comparação referentes à composição de valores, sendo que um deles apresentava o valor contido na nota ou na moeda modelo. A segunda tarefa consistiu na apresentação de uma nota ou de uma moeda como estímulo-modelo e a resposta da participante foi a de construção desse valor, estando disponíveis para ela outras seis notas ou moedas que combinadas somavam o valor da nota ou da moeda modelo. A terceira tarefa consistiu na apresentação, como estímulo-modelo, de objetos e os seus preços impressos em valores, utilizando-se tanto a casa dos reais quanto a casa dos centavos. Os objetos utilizados e seus respectivos valores foram: paçoca $(\mathrm{R} \$ 0,25)$; sabonete $(\mathrm{R} \$ 1,20)$; livro $(\mathrm{R} \$ 20,05)$; sapato $(\mathrm{R} \$ 50,10)$; rádio $(\mathrm{R} \$ 100,00)$. A resposta da participante foi a de construção desse valor e para isso, estiveram disponíveis seis notas e moedas que combinadas somavam o valor impresso no objeto. Caso o desempenho da participante não fosse de $100 \%$ de acertos em qualquer uma das três tarefas, seria realizado, nas condições de ensino já descritas, o ensino da primeira. Após dois blocos consecutivos de $100 \%$ de acertos as outras duas tarefas seriam testadas novamente.
Por fim, a terceira fase do estudo consistiu na montagem, pelo experimentador, de um ambiente que simulava uma loja, parecida com alguma loja que a participante estivesse acostumada a frequentar, e uma saída de casa com o cuidador para um ambiente real de compra. Foi montada na casa da idosa uma miniloja, composta de uma estante contendo alguns objetos, tais como os já utilizados na segunda fase (paçoca, sabonete, livro, sapato e rádio) e outros objetos que a participante declarou, ao longo do estudo, gostar ou querer. Os respectivos preços eram colados nos próprios objetos. Foram fornecidas à idosa instruções do procedimento de compra e entregue o valor de dez reais em notas e moedas, segundo a seguinte composição: uma nota de cinco reais, uma nota de dois reais, duas moedas de um real, uma moeda de $\mathrm{R} \$ 0,50$, uma moeda de $\mathrm{R} \$ 0,25$, duas moedas de $\mathrm{R} \$ 0,10$ e uma moeda de R $\$ 0,05$. Solicitou--se à participante que comprasse na "lojinha" o que ela pudesse e quisesse consumir, deixando que a mesma administrasse o dinheiro. Foi permitido auxílio quando os pedidos de ajuda fossem feitos.

No ambiente real, o cuidador e o experimentador acompanharam a participante e entregaram-lhe a mesma quantia em dinheiro que foi entregue no ambiente simulado (incluindo notas e moedas) para que a participante comprasse, nesse estabelecimento, o que ela pudesse e quisesse consumir, deixando que a mesma administrasse o dinheiro. Mais uma vez, foi permitido auxílio quando o pedido de ajuda fosse feito.

A tabela 1 apresenta uma síntese das condições experimentais do estudo.

Tabela 1

Síntese das Condições Experimentais, Contendo a Identificação de Cada Condição, o Critério de Desempenho e as Relações

\begin{tabular}{cllll}
\hline Fase & Condição Experimental & \multicolumn{1}{c}{ Critério } & \multicolumn{1}{c}{ Relações } & \multicolumn{1}{c}{ Estímulos } \\
\hline $\begin{array}{c}\text { Treino } \\
\text { MTS }\end{array}$ & Treino Identidade & $\begin{array}{l}100 \% \text { de acertos } \\
\text { em um bloco }\end{array}$ & $\begin{array}{l}\text { Figura de pessoa famo- } \\
\text { sa/figura de pessoa famosa }\end{array}$ & $\begin{array}{l}\text { Pelé, Chacrinha, Carmem Miranda, Roberto Carlos, } \\
\text { Elvis Presley e Orlando Silva }\end{array}$ \\
& & $\begin{array}{l}100 \% \text { de acertos } \\
\text { em um bloco }\end{array}$ & $\begin{array}{l}\text { Figura de pessoa famo- } \\
\text { sa/nomeação }\end{array}$ & $\begin{array}{l}\text { Pelé, Chacrinha, Carmem Miranda, Roberto Carlos, } \\
\text { Treino Nomeação }\end{array}$ \\
\end{tabular}

Testes iniciais $B B, A B, A^{\prime} C, C B, B C, D B, B D, B E, C E, C C^{\prime}, A^{\prime} C^{\prime}, C^{\prime} E, A^{\prime} F, A^{\prime} F^{\prime}, F F$, BF, FB, FE e F'E

1

$100 \%$ de acertos

Ensino FE em dois blocos consecutivos

Figura da moeda/nomeação $\quad \mathrm{R} \$ 0,05 ; \mathrm{R} \$ 0,10 ; \mathrm{R} \$ 0,25 ; \mathrm{R} \$ 0,50$ e $\mathrm{R} \$ 1,00$

Testes FE e F'E 


\begin{tabular}{|c|c|c|c|c|}
\hline Fase & Condição Experimental & Critério & Relações & Estímulos \\
\hline \multirow{4}{*}{2} & Teste Primeira Tarefa & $\begin{array}{l}100 \% \text { de acertos } \\
\text { em um bloco }\end{array}$ & Nota ou Moeda/Composição & Notas ou moedas \\
\hline & Teste Segunda Tarefa & $\begin{array}{l}100 \% \text { de acertos } \\
\text { em um bloco }\end{array}$ & Nota ou moeda/Construção & Notas ou moedas \\
\hline & Teste Terceira Tarefa & $\begin{array}{l}100 \% \text { de acertos } \\
\text { em um bloco }\end{array}$ & $\begin{array}{l}\text { Objetos e seus valo- } \\
\text { res/Construção }\end{array}$ & Notas, moedas e objetos \\
\hline & Ensino Primeira Tarefa & $\begin{array}{l}100 \% \text { de acertos } \\
\text { em dois blocos } \\
\text { consecutivos }\end{array}$ & Nota ou Moeda/Composição & Notas ou moedas \\
\hline \multicolumn{5}{|c|}{ Testes Segunda e Terceira Tarefa } \\
\hline \multirow{2}{*}{3} & "Lojinha" & - & $\begin{array}{l}\text { Objetos e seus valo- } \\
\text { res/Construção }\end{array}$ & Notas, moedas e objetos \\
\hline & Loja Real & - & $\begin{array}{l}\text { Objetos e seus valo- } \\
\text { res/Construção }\end{array}$ & Notas, moedas e objetos \\
\hline
\end{tabular}

\section{RESULTADOS}

A análise dos resultados foi conduzida por meio do delineamento experimental de sujeito como o seu próprio controle.

$\mathrm{Na}$ tarefa de identidade do treino preparatório para o responder condicional, na qual as seis figuras de pessoas famosas foram utilizadas como estímulos modelo e de comparação, a idosa precisou de apenas dois blocos para o alcance do critério. No primeiro bloco a idosa apresentou um desempenho de $16 \%$ de acertos. Entretanto, após as correções e uma nova explicação da tarefa, seu desempenho no bloco 2 foi de $100 \%$ de acertos. Tal dado mostra que possivelmente a participante não entendeu a instrução no primeiro bloco, já que suas escolhas eram aleatórias.

Nas tarefas de nomeação, foram necessários oito blocos para que a participante alcançasse o critério. Nos blocos 1 e 2 utilizou-se o procedimento de correção descrito anteriormente. A partir do bloco 3, um novo procedimento de auxílio foi utilizado. $\mathrm{O}$ experimentador fornecia à participante apenas o primeiro nome do modelo e esperava que a participante o completasse. A idosa completou corretamente todos os sobrenomes a partir das dicas fornecidas, entretanto não foi considerado um acerto quando tal dica era fornecida. A causa da queda de acertos do bloco 4 para o 5 deve-se ao fato que as mesmas foram feitas em um intervalo de 1 semana. A partir do bloco 5 observou-se que a resposta "não sei" da participante era fornecida antes mesmo de olhar para o estímulo. Introduziu-se um novo procedimento de auxílio, em que era fornecido pelo experimentador um intervalo maior antes da resposta correta e uma instrução para que a participante pensasse um pouco mais quem era o modelo. Tal procedimento resultou em alguns acertos da participante nos blocos 6 e 7 e em $100 \%$ de acertos no bloco 8 . Considerou-se que o repertório necessário para o responder condicionalmente havia sido instalado.

A Figura 3 mostra os resultados obtidos nos testes de avaliação do repertório de entrada da participante. 


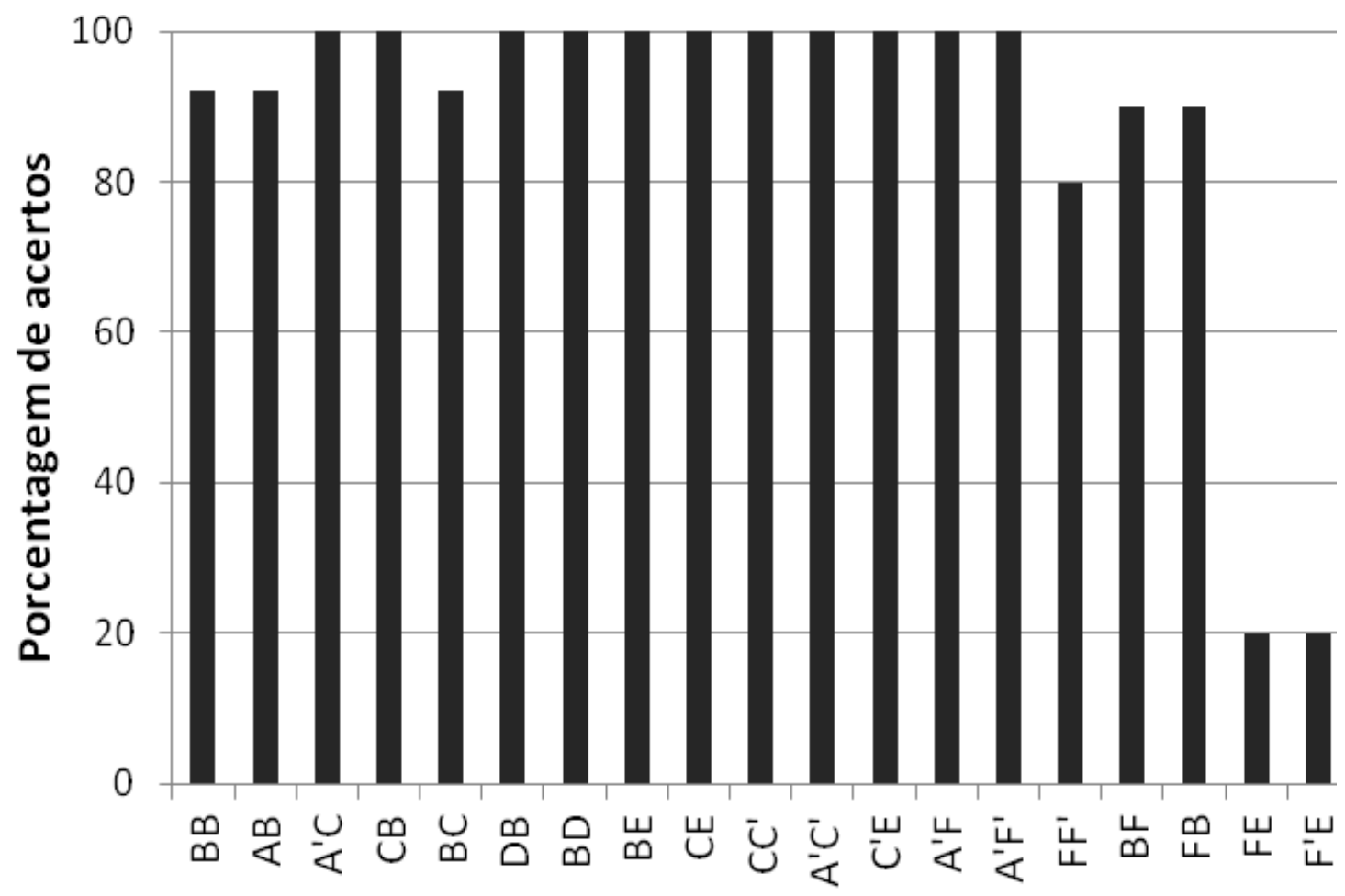

Relações testadas

Figura 3. Resultados dos testes de avaliação do repertório de entrada da participante referente à primeira fase. Cada barra indica a relação das tarefas testadas.

Nos testes $\mathrm{A}^{\prime} \mathrm{C}, \mathrm{CB}, \mathrm{DB}, \mathrm{BD}, \mathrm{BE}, \mathrm{CE}, \mathrm{CC}$ ', A'C', C'E, A'F e A'F' a participante apresentou $100 \%$ de acertos. Nos testes $\mathrm{BB}, \mathrm{AB}$ e $\mathrm{BC}$ seus acertos foram de 11 em 12 tentativas representando $92 \%$ de acertos. Já nos testes BF e FB, a participante acertou nove em 10 tentativas, configurando em $90 \%$ de acertos. No teste FF' seus acertos foram oito em 10, totalizando $80 \%$ de acertos. As únicas relações em que os acertos da participante ficaram abaixo do nível do acaso foram nos testes FE (figura da moeda/nomeação) e F'E (moeda $\mathrm{real} /$ nomeação). Os erros ocorreram quando foi preciso distinguir um valor em real de um valor em centavos de real, isso porque a participante nomeou todas as moedas como possuindo valor de real (Ex.: "cinco reais" quando o modelo era cinco centavos).
Optou-se então por ensinar à participante a relação FE. Para tal, foi utilizado um novo procedimento em que a primeira tarefa continha apenas como estímulo-modelo a moeda de um real. A segunda tarefa continha apenas a moeda de $\mathrm{R} \$ 0,50$ como estímulo-modelo. A partir da terceira tarefa, eram apresentados dois estímulos-modelos, sendo constituídos de uma moeda já ensinada e outra a ser ensinada. Apontava-se para a idosa o estímulo que ela deveria nomear. Seguiu-se introduzindo uma moeda nova a cada nova tarefa até que ao término da última tarefa contivesse todas as moedas como estímulo-modelo (FE - misto). Os resultados do treino são apontados na Figura 4. 


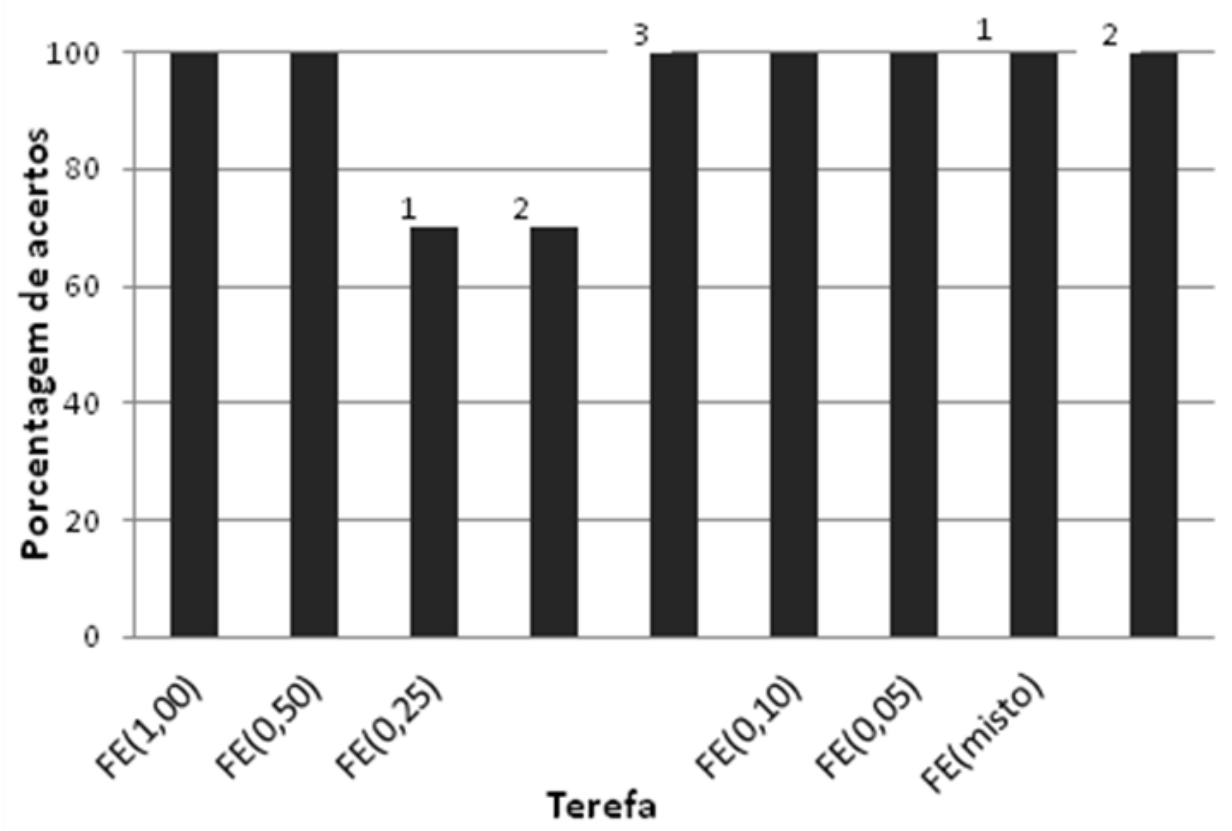

Figura 4. Resultados do ensino da relação FE à participante. Cada barra indica a tarefa ensinada. Os números acima das barras de $\mathrm{FE}(0,25)$ e $\mathrm{FE}$ (misto) indicam que foi necessário mais de um bloco para o alcance de critério.

No treino da primeira tarefa, $\mathrm{FE}(1,00)$, e da segunda tarefa, $\operatorname{FE}(0,50)$ a participante apresentou $100 \%$ de acertos logo no primeiro bloco. Já no treino da terceira tarefa, $\mathrm{FE}(0,25)$, quando se introduziu um novo modelo, foram necessários três blocos para que o critério fosse alcançado, sendo que nos dois primeiros blocos o acerto da participante foi de $70 \%$ e no terceiro foi alcançado o critério de $100 \%$ de acertos. No ensino das outras tarefas, $\operatorname{FE}(0,10)$ e $\operatorname{FE}(0,05)$ a participante alcançou o critério em apenas um bloco. O critério, no treino da tarefa $\mathrm{FE}$ (misto), foi alcançado com a apresentação do mínimo de dois blocos requeridos.

Nos testes após o ensino da relação FE a participante apresentou $100 \%$ de acertos nas relações FE e F'E. Observou-se em ambos os testes o aumento do repertório de autocorreção da participante. Esse fato pode ser observado, por exemplo, nas tentativas 3 e 7 do teste $\mathrm{FE}$, quando a participante primeiramente mencionou o estímulo-modelo com um valor de real, e imediatamente, sem a interferência do experimentador, corrigiu-se e nomeou corretamente as moedas e seus valores em centavos de real. O mesmo pode ser observado no teste $F$ 'E frente às tentativas $1 \mathrm{e} 2$. Além disso, a participante também demostrou, espontaneamente, que sabia diferenciar em valor real dos centavos de real, falando que o real era maior que os centavos de real ("as notas valem mais que as moedas").
$\mathrm{Na}$ primeira tarefa da segunda fase a participante errou apenas uma tentativa de 20 , totalizando $95 \%$ de acertos. Tal erro deveu-se ao fato da participante enxergar na moeda de um real o numeral cinco. Na moeda de um real uma faixa curvada, ligada ao numeral 1, passa acima da palavra "real", e essa configuração assemelha-se à parte curva do numeral 5. Essa dimensão do estímulo muito provavelmente controlou a verbalização da participante. Desse modo, embora não tenha conseguido de fato somar corretamente os estímulos de comparação e encontrar a resposta correta, se levarmos em conta o fato de que a moeda de um real era para a participante uma moeda de cinco reais, ela somou corretamente os estímulos de comparação. Tal tarefa foi considerada satisfatória e não houve a necessidade de reaplicação, uma vez que o erro cometido não teve influência sobre o comportamento de somar corretamente. Na segunda tarefa houve a realização de dois blocos, já que durante a realização do primeiro notou-se que a participante, apesar de mostrar um bom desempenho (85\%), estava muito agitada e dispersa, fato esse observado também pela cuidadora e justificado pelo atraso da idosa ao voltar para a sua casa de uma visita à filha. Quando reaplicado o teste segunda tarefa, o desempenho da idosa foi de $75 \%$ de acertos, sendo que os erros da participante não aconteceram por falta de dispersão e desatenção. Foi observado, entretanto, que seu responder não estava sob 
controle do estímulo-modelo e da instrução fornecida. $\mathrm{Na}$ terceira tarefa, a idosa acertou a composição de três objetos, de um total de cinco (60\%). Observou-se mais uma vez que o responder poderia não estar sob controle do modelo e/ou da instrução.

Optou-se, então, pela realização do ensino da segunda tarefa e dos pós-teste da segunda e terceira tarefa. $\mathrm{O}$ ensino de tal tarefa seguiu o procedimento de auxílio descrito nesse trabalho, em que era solicitado à participante que apontasse e nomeasse o estímulo-modelo e todos os estímulos de comparação antes de fornecida a instrução de construção.

No ensino da segunda tarefa, a participante necessitou de três blocos para que o critério de acertos dois blocos consecutivos de $100 \%$ de acertos fosse alcançado. No primeiro bloco a participante acertou $60 \%$ das tentativas. Os erros da participante foram basicamente dois, sendo um relativo ao seu comportamento não estar sob controle do estímulo-modelo, uma vez que somava toda a quantia de dinheiro disposta como estímulos de comparação; e outro relativo à confusão entre centavos de real e real. Entretanto, mesmo em algumas tentativas nomeadas equivocadamente, a participante conseguiu fazer corretamente a construção dos valores. Ainda, nas duas últimas tentativas, antes que fosse solicitado à participante que nomeasse os estímulos, ela perguntou à experimentadora se o valor que deveria somar era aquele contido no estímulo-modelo, como por exemplo: "Você quer vinte, né?". O segundo bloco, apesar de uma porcentagem de acertos de $95 \%$, foi considerado como satisfatório para o alcance do critério, uma vez que a participante acertou o valor da composição mesmo nomeando uma moeda de $\mathrm{R} \$ 0,25$ como sendo de 25 reais. No terceiro bloco, a participante obteve $100 \%$ de acertos, sendo que em nove tentativas (de 20) a idosa perguntou à experimentadora se o valor que deveria somar era aquele contido no estímulo-modelo. Pode-se notar também uma diminuição no tempo de resposta da participante entre o primeiro bloco e os outros dois.

Após o ensino, no teste da segunda tarefa, a participante apresentou $85 \%$ de acertos. Durante a primeira tentativa a participante nomeou espontaneamente todos os estímulos presentes. Ainda, em quatro outras tentativas a participante não precisou da instrução para saber qual seria o valor a somar. Entretanto, ela mostrou, novamente, certa dificuldade com a moeda de um real. Além disso, em duas tentativas consideradas incorretas, o comportamento da participante mostrou-se mais uma vez não estar sob controle do modelo e da instrução. Na última tentativa, houve a interfe- rência externa do telefone da casa que tocou e distraiu a participante. Com relação ao pós-teste da terceira tarefa, a participante apresentou $100 \%$ de acertos na construção dos valores dos objetos. Na construção do valor do sapato a participante mostrou certa dificuldade e um maior tempo de resposta, entretanto, conseguiu sem auxílio da experimentadora, corrigir-se e entregar o valor correto.

A terceira fase do estudo foi então introduzida. Antes de começar a "comprar", a idosa questionou se o dinheiro dado a ela daria para "pagar", então foi fornecida novamente a informação da quantia que ela possuía e explicado que ela deveria escolher os itens até esse valor total. As primeiras escolhas da participante foram um sabonete no valor de $\mathrm{R} \$ 1,20$, uma gelatina no valor de $\mathrm{R} \$ 0,50$ e um bolinho também no valor de R\$0,50. Quando questionada sobre o quanto já tinha comprado a idosa pôs-se a somar: primeiro o sabonete e a gelatina com soma igual a $\mathrm{R} \$ 1,70$. Entretanto, a participante respondeu que o valor era de $\mathrm{R} \$ 2,70$. Foi incentivada a somar mais duas vezes, entretanto continuava persistindo no erro quando era questionada quanto tinha dado a soma para que o próximo item fosse adicionado a conta. A soma certa foi fornecida pela experimentadora. Quando adicionou na soma o outro objeto escolhido, perguntou à experimentadora quanto tinha dado a soma. A questão foi então devolvida a ela e sem olhar para os objetos disse novamente $\mathrm{R} \$ 2,70$. Foi mais uma vez instruída a somar os dois objetos e acertou o resultado. Quando solicitada a continuar somando, adicionou corretamente o outro objeto a conta $(\mathrm{R} \$ 2,20)$. Nesse momento, a experimentadora perguntou à idosa se ela gostaria de comprar mais alguma coisa e ela escolheu um bombom no valor de $\mathrm{R} \$ 0,35$. Instruída a continuar a soma, não conseguiu recordar o valor que havia calculado anteriormente, e a soma dos objetos já escolhidos foi novamente realizada. Apesar de somar corretamente, não transformou os centavos de reais em reais, ou seja, somou 220 reais. Questionada sobre o valor, foi feita uma nova soma do que já havia sido comprado e acrescentado o bombom, totalizando $\mathrm{R} \$ 2,55$, corretamente. Instruída a pagar a conta, a idosa pegou o dinheiro e perguntou novamente quanto era o valor que deveria ser pago. Foi fornecido pela experimentadora o valor total, uma vez que o objetivo da tarefa era apenas verificar se a idosa somava corretamente e se conseguia construir o valor necessário para pagar a compra e não verificar a memória de curto prazo. Durante os próximos dois minutos e meio a participante questionou mais quatro vezes qual era o valor 
total da compra e resposta anteriormente foi fornecida pela experimentadora. Ao final, ela entregou a experimentadora o valor correto da soma.

Após a realização da tarefa de compra em um ambiente simulado, a idosa juntamente com a sua cuidadora, foi levada a uma loja de conveniência em um posto de combustível que fica perto de sua casa. As mesmas instruções de compra e a mesma quantia em dinheiro da tarefa anterior foram fornecidas à idosa em uma mesa localizada fora da loja. Ao entrar na loja, a idosa escolheu sozinha dois chocolates, um no valor de $\mathrm{R} \$ 1,50$ e outro no valor de três reais e o somou-os corretamente. Logo depois, a idosa questionou a experimentadora sobre qual era o lugar para pagar o que havia comprado. Depois de mostrado à idosa onde ficava o caixa, o experimentador e a cuidadora acompanharam-na até o caixa. A idosa pegou então uma nota de cinco reais e entregou à operadora do caixa. A experimentadora perguntou para a idosa quanto era $\mathrm{o}$ troco que deveria receber e ela respondeu corretamente o valor de $\mathrm{R} \$ 0,50$. Essa fase desenvolveu-se de maneira bem satisfatória e rápida, uma vez que não se observou problemas com o ato de compra e resolução das contas, inclusive a de subtração relacionada ao troco.

\section{DISCUSSÃO}

Os objetivos do presente estudo foram: a) sistematizar um conjunto de testes iniciais para verificação de habilidades numéricas e de uso de dinheiro em idoso com perda inicial de memória; b) a partir dos resultados obtidos com os testes, programar estratégias de ensino para o estabelecimento de habilidades no uso de dinheiro e; c) verificar a generalização das habilidades aprendidas para situações cotidianas. $\mathrm{O}$ procedimento adotado contribuiu na sistematização de um conjunto de testes para a verificação de parte das habilidades numéricas e de uso de dinheiro e ofereceu, a partir desses testes, possibilidades de ensino de habilidades numéricas a uma idosa com perda inicial de memória. Entretanto, faz-se necessário o aperfeiçoamento do procedimento assim como o aumento do número de participantes expostos ao procedimento de ensino.

O procedimento de treino preparatório para instalar comportamentos essenciais para responder condicionalmente parece ter sido até certo ponto eficiente, já que os resultados mostram uma curva positiva de aprendizagem da idosa. Entretanto, durante várias partes do estudo as respostas da idosa pareceram não estar sob controle do estímulo-modelo, condição essencial para responder condicionalmente. Por não haver a possibilidade de estar sob controle do estímulo-modelo fica difícil afirmar se a idosa não havia aprendido as habilidades numéricas ou a tarefa de MTS. Sendo assim, sugere-se introduzir, em estudos futuros, algumas reaplicações desse treino, durante as outras fases do estudo, sempre que necessário, a fim de garantir o responder condicional e um controle maior sobre as repostas dos participantes, se eles sabem ou não as habilidades numéricas ou a tarefa em si.

A utilização de dicas durante o procedimento do treino preparatório para o responder condicional parece ter favorecido também a aprendizagem, como mostra o estudo de McLellan (1991). Houve a facilitação da memória explicita residual da idosa quando foi fornecido a ela somente o primeiro nome da pessoa famosa em questão, o que a ajudou a lembrar. Ainda, foi utilizado um procedimento de dicas no relacionamento entre a experimentadora e a participante, no que se diz respeito a lembrar o nome da experimentadora. Era fornecida a primeira sílaba do nome e esperado que a idosa completasse, a fim de que lembrasse o nome. Nas últimas sessões com a participante, ela lembrou, sem auxílio externo, o nome e outras informações pessoais sobre a experimentadora.

O conjunto de testes utilizados para verificar o repertório de entrada da participante e com isso parte da sua capacidade financeira (do original em inglês, $f i$ nancial capacity, utilizado na literatura internacional), parece ter sido o resultado mais importante do estudo. Como já citado, são poucos os estudos que avaliam a capacidade financeira de idosos demenciados (Ernst et al., 2001; Marson, 2001; Marson et al., 2000; Martin, 2008; Martin et al., 2003) e no Brasil eles não existem. Não há testes padronizados para a avaliação de tal habilidade, o que justificaria por si só o desenvolvimento de um conjunto de testes para a avaliação das mesmas. Sabe-se ainda que a utilização por parte do experimentador, do relato verbal do cuidador sobre a capacidade financeira dos idosos pode não ser confiável. Wadley, Harrell e Marson (2003) mostraram por meio da comparação de testes que mediam a capacidade financeira e dos relatos verbais dos cuidadores que, muitas vezes o cuidador subestima ou superestima a capacidade financeira dos idosos com DA. Cabe ainda ressaltar que a aplicação de testes eficientes que avaliem a capacidade financeira do idoso é de extrema importância, uma vez que é a partir deles que teremos um repertório de entrada bem estabelecido a fim de verificar posteriormente, se o procedimento de ensino 
em questão é o principal fator da aprendizagem do idoso.

O ensino da relação FE (figura da moeda/nomeação) na primeira fase do estudo mostrou-se efetivo, dado este confirmado no pós-teste realizado. Ainda pode-se observar a emergência da nomeação do estímulo "figura da moeda" para a "moeda real", na relação F'E (moeda real/nomeação) que não foi anteriormente treinada. Ainda, na segunda fase do estudo, depois de ensinada apenas a segunda tarefa, a terceira tarefa foi testada e a participante alcançou $100 \%$ de acertos sinalizando emergência da relação não ensinada. Tal fato corrobora os achados de Sidman e Tailby (1982) e sugere que as relações condicionais da rede de ensino foram bem estabelecidas, uma vez que o ensino de apenas uma relação deu origem a outra relação não diretamente treinada.

Ainda na segunda fase do estudo, foi possível observar que, apesar de o resultado quantitativo não estabelecer uma aprendizagem total da tarefa (85\% de acertos no pós-teste), houve uma melhora qualitativa no responder da idosa. Isso pode ser notado na diminuição, do tempo de resposta da idosa, e consequentemente da realização da tarefa, e da diminuição dos erros de nomeação das moedas. Ainda verificou-se que a idosa mostrava-se com menos dificuldade no reconhecimento da moeda de um real.

No que se diz respeito à terceira fase do estudo, apesar de a idosa mostrar algumas dificuldades na tarefa de simulação de uma Loja, seu desempenho no ambiente real foi plenamente satisfatório. Entretanto, não é possível afirmar que ocorreu generalização dos procedimentos de ensino para o ambiente real, uma vez que, não foram feitos pré-testes para verificar a capacidade de compra da idosa. Sugere-se então, acrescentar nos testes avaliativos uma tarefa de compra em um ambiente simulado a fim de não expor o idoso a possíveis situações constrangedoras no ambiente real.

De maneira geral, o estudo mostrou resultados promissores e uma economia de ensino, visto que, por meio de procedimentos de discriminações condicionais e equivalência de estímulos, houve a aprendizagem de relações que não foram diretamente treinadas. Além disso, contribui, juntamente com o estudo de Pérez-González e Moreno-Sierra (1999), para que se quebre o tabu de que idosos com perda de memória e/ou demência não aprendem. Acrescenta-se ainda um importante papel desempenhado pelo estudo: o de iniciar a criação de um conjunto de testes que verifi- quem de maneira eficiente parte da capacidade financeira de idosos com DA, uma vez que o relato verbal dos próprios idosos e dos seus cuidadores pode não ser confiável.

\section{REFERÊNCIAS}

Arkin, S. (2000). Alzheimer memory training: Students replicate learning success. American Journal of Alzheimer's Disease and Other Dementias, 15, 152-167.

Arnaud, L., Lemaire, P., Allen, P., \& Michel, B. F. (2008). Strategic aspects of young, healthy older adults', and Alzheimer patients' arithmetic performance. Cortex, 44, 119-130.

Brucki, S. M. D., Nitrini, R., Caramelli, P., Bertolucci, P. H. F., \& Okamoto, I. H. (2003). Sugestões para o uso do Mini-Exame do Estado Mental no Brasil. Arquivos de Neuropsiquiatra, 61, 777-781.

Catania, A. C. (1999). Aprendizagem: Comportamento, linguagem e cognição ( $4^{\mathrm{a}}$ ed.). (D. G. Souza., Trans.). Porto Alegre: ArtMed.

Clare, L., Wilson, B., \& Carter, G. (2000). Intervening with everyday memory problems in dementia of Alzheimer type: An errorless learning approach. Journal of Clinical and Experimental Neuropsychology, 22, 132-146.

Clare, L., Wilson, B., \& Carter, G. (2001). Long-term maintenance of treatment gains following a cognitive rehabilitation intervention in early dementia of Alzheimer type: A single case study. Neuropsychological Rehabilitation, 11, 477-494.

Deloche, G., Hannequin, D., Carlomagno, S., \& Agniel, A. (1995). Calculation and number processing in mild Alzheimer's disease. Journal of Clinical Experimental Neuropsychology, 17, 634-639.

Earnst, K, Wadley, V., Aldridge, T., Steenwyk, A., Hammond, A., Harrell, L., \& Marson, D. (2001). Loss of financial capacity in Alzheimer's disease: The role of working memory. Aging, Neuropsychology, and Cognition, 8, 109-119.

Katz, S., Ford, A. B., Moskowitz, R. W., Jackson, B. A., \& Jaffe, M. W. (1963). Studies of illness in the aged. The index of ADL: A standardized measure of biological and psychosocial function. Journal of the American Medical Association, 85, 914-920.

Kixmiller, J. S. (2002). Evaluation of prospective memory training for individuals with mild Alzheimer's disease. Brain and Cognition, 49, 237-241.

Mantovan, M. C., Delazer, M., Ermani, M., \& Denes, G. (1999). The breakdown of calculation procedures in Alzheimer's disease. Cortex, 35, 21-38.

Marson, D. C., Sawrie, S. M., Snyder, S., McInturff, B., Stalvey, T., Boothe, A., Aldridge, T., Chatterjee, A., \& Harrell, L. E. (2000). Assessing financial capacity in patient with Alzheimer's disease: A conceptual model and prototype instrument. Archives of Neurology, 57, 877-884.

Marson, D. C. (2001). Loss of financial capacity in dementia: Conceptual and empirical approaches. Aging Neuropsychology and Cognition, 8, 164-181.

Martin, R.C., Annis, S. M., Darling, L. Z., Wadley, V., Harrell, L., \& Marson, D. C. (2003). Loss of calculation abilities in pa- 
tients with mild and moderate Alzheimer disease. Archives of Neurology, 60, 1585-1589.

Martin, R. C. (2008). Declining financial capacity in patients with mild Alzheimer disease: A one-year longitudinal study. American Journal of Geriatric Psychiatry, 16, 209-219.

Maylor, E. A., Watson, D. G., \& Muller, Z. (2005). Effects of Alzheimer's disease on visual enumeration. Journal of Gerontology - Series B: Psychological Sciences and Social Sciences, 60, 129-135.

McLellan, D. L. (1991). Functional recovery and principles of disability medicine. In M. Swash \& J. Oxbury (Eds.), Clinical neurology (pp. 768-790). London: Churchill Livingstone.

Nygård, L. (2003). Instrumental activities of daily living: A stepping-stone towards Alzheimer's disease diagnosis in subjects with mild cognitive impairment? Acta Neurologica Scandinavica, 107, 42-46.

Parlato, V., Lopez, O. L., Panisset, M., \& Iavarone, A. (1992). Mental calculation in mild Alzheimer's disease: A pilot study. International Journal of Geriatric Psychiatry, 7, 599-602.

Pérez-González, L. A., \& Moreno-Sierra, V. (1999). Equivalence class formation in elderly persons. Psicothema, 11, 325-336.
Rosselli, M, Ardila, A., Arvizu, L., Kretzmer, T., Standish, V., \& Liebermann, J. (1998). Arithmetical abilities in Alzheimer disease. International Journal of Neuroscience, 96, 141-148.

Rossit, R. A. S., \& Goyos, C. (2004). Matemática para deficientes mentais: Contribuições do paradigma de equivalência de estímulos. Política, Conhecimento e Cidadania, 1, 1-18.

Sidman, M. (2000). Equivalence relations and the reinforcement contingency. Journal of the Experimental Analysis of Behavior, 74, 127-146.

Sidman, M., \& Tailby, W. (1982). Conditional discrimination vs. matching to sample: An expansion of the testing paradigm. Journal of the Experimental Analysis of Behavior, 37, 5-22.

Wadley, V. G., Harrell, L. E., \& Marson, D. C. (2003). Self- and informant report of financial abilities in patients with Alzheimer's disease: Reliable and valid? Journal of the American Geriatric Society, 51, 621-1626. 